\title{
The context of contextualizing contexts
}

\author{
Friederike Welter, William B. Gartner and Mike Wright
}

\section{Why context is interesting: personal viewpoints}

Friederike: For me, context has always played a role, implicitly and more recently, explicitly. I see it as a theme running through my research career and life, influencing the topics I study and how I do research. When I started my research career, it was in a policy-oriented research institute outside academia, in multicultural teams and with the theme of entrepreneurship in post-Soviet countries (or, even earlier, for my doctoral thesis collecting data on informal ventures in Nigeria - see Welter [2016]). I have worked and lived in so many different and diverse contexts, which again and again made me aware of the role of context in creating differences between entrepreneurs and their behaviour. It also has made me more and more intolerant of our universalized claims for entrepreneurship across the world.

I have set out my context ideas explicitly in Welter $(2008,2011)$, where I took stock of what I had learned from my research in different contexts since the early $1990 \mathrm{~s}$ and developed my insights into a few ideas on how contextualization could further entrepreneurship research. The 2011 paper focused on showing why context mattered, what context is in entrepreneurship research and what contextualizing entrepreneurship (research) means. I reviewed the multiplicity and intersectionality of contexts, going beyond the business context and looking at social contexts (households, families and community), the spatial context of neighbourhoods, communities and regional cultures and the institutional contexts. Also, I see close links between the context theme and gender (Welter, Brush and de Bruin 2014), context and entrepreneurship policies (Welter and Smallbone 2011b) and resourcefulness/entrepreneurial behaviour across contexts (Welter and Smallbone 2011a; Welter and Xheneti 2013). To sum up, for me, contextualization is about recognizing differences. Thus, a contextualized understanding of entrepreneurship questions our tendency for an 'all-are-alike' approach. Thus, context matters as it contributes to and determines differences in entrepreneurship.

Currently, I am particularly interested in what to do with this insight: how can we contextualize theories, especially theory-building? And what does context mean for entrepreneurship policies? How can we incorporate temporal and historical contexts? How are process and contexts linked and how to make sense of this? How to 
theorize that entrepreneurs also influence contexts? And, on a more practical level, how to conduct meaningful contextualized empirical research?

Bill: My interest in contextual perspectives in entrepreneurship stems from my initial experiences of interviewing entrepreneurs for my dissertation (Gartner 1982). A retrospective sense-making of that research effort can be found in Gartner (Gartner 2008). The dissertation spawned two articles, a theoretical paper in which I offered the insight that there is a great amount of variation in the kinds of: entrepreneurs, processes, organizations, and, environments that might be observed when looking at new venture start-ups (Gartner 1985), and an empirical paper (Gartner, Mitchell and Vesper 1989) where an attempt was made to show how specific start-ups might be grouped across these four dimensions. What often gets lost in looking at entrepreneurial phenomena is the uniqueness of each situation. I believe that we tend, as scholars, to look for generalizable insights from our data, and, therefore, overlook the many differences that exist among the various startups in our studies. My initial struggle was in trying to figure out whether any kind of generalizable findings might be ascertained from the cases in my dissertation. It seemed, at one level, each start-up case was so different from the others that no apparent logic could be offered for finding a basis for generalizing insights from one case to another. Characteristics of these individuals were often so different. They had different backgrounds, different interests, and different ways at looking at the situations they were in. The kinds of business they started varied across so many industries, and the ways that these new businesses entered their markets were often very different as well. And, the ways that these new firms came into existence was never described in the same way. And, finally, the environments in which these new businesses were founded were never exactly the same: different industries, different locations, different networks of individuals, different types of customers and suppliers. The aphorism that came out of this attempt at finding similarities among was 'There is no average in entrepreneurship' (Gartner, Mitchell and Vesper 1989, p. 184).

So, I have tried to carry this viewpoint forward: entrepreneurship is about variation and that the differences among entrepreneurial situations are likely to be as significant as the variation (in the characteristics of the situation) that might exist between entrepreneurial and non-entrepreneurial situations. I think there is often a misreading of the article "Who is an entrepreneur?" is the wrong question' (Gartner 1988) that would suggest I do not believe that the characteristics of entrepreneurs play a factor in determining aspects of the development of new ventures. I think a more accurate reading of that article is that I believe that the characteristics of entrepreneurs matter, but only in that those characteristics are linked to specific entrepreneurial situations, and, for the most part those specific entrepreneurial situations vary so widely that finding a common individual characteristic would seem to be pointless. Context matters. Assuming that a 'one-size-fits-all' kind of entrepreneur exists, who could act entrepreneurial in all situations, would seem to be very unlikely. I think the only way one might find characteristics of individuals that have strong correlations to their situations, is to narrow the context of these 
situations. There is a person-situation fit (Shaver and Scott 1991) that needs to be accounted for.

Where I believe there might be some way of finding commonalities among start-up situations is to look at the kinds of activities these individuals engage in. And, even in looking at start-up activities, I believe my research has shown that there are various sequences of behaviours, rather than one set formula of entrepreneurial activity (Carter, Gartner and Reynolds 1996; Gartner, Carter and Reynolds 2004).

So, finding commonalities among entrepreneurial situations: difficult. And, I believe the reason that a growing focus on 'context' has occurred, is that when researchers look closely at the situations where entrepreneurship occurs, they see 'difference' rather than similarities. Context matters because entrepreneurial situations are so very different.

Friederike: Was Hjorth, Jones and Gartner (2008) the first Special Issue on context in entrepreneurship?

Bill: I think this special issue was an attempt to offer a 'counter-narrative' to 'taken-for-granted' assumptions about the nature of entrepreneurship. The idea of context addressed in the special issue introduction as important to consider was due to the reason that the situations that are assumed to be entrepreneurial have been 'taken-for-granted', yet upon closer inspection most situations in which entrepreneurship occurs appear to be very different from one-another. The papers that are presented in that special issue are examples of various contexts that are not necessarily 'taken-for-granted'.

But, if I were to look for an effort where context was fundamental to expressing differences in the nature of entrepreneurial phenomena, then, it would be much earlier: The Journal of Business Venturing Special Issue on Qualitative Methods (Gartner and Birley 2002). If one looks at that issue of the journal, then, there is a variety of contexts (Nigeria, Sri Lanka, the life histories and social contexts of a start-up, metaphors used in the media) that were not typical, at this point, of entrepreneurial situations, currently explored in most mainstream entrepreneurship journals. One observation from our efforts to shepherd those special issue articles to publication was that the entrepreneurship field needed to recognize a larger body of research across a wider range of sources, contexts and genres. We offered the idea of the 'critical mess' as a metaphor for collecting different information about different kinds of entrepreneurships as a way to enrich our understanding of the entirety of entrepreneurship as a phenomenon.

Mike: My positions on the role and nature of context in entrepreneurship have been set out, inter alia in Zahra and Wright (2011), Autio et al. (2014) and Wright et al. (2014). In these papers, I have sought to articulate the multiple dimensions of contexts, notably institutional, geographical, technological, industrial, organizational, temporal and social. I also take the view that context is dynamic and 
continually evolving and that we need to take account of this both in developing and testing theory. These different contexts have implications for the nature and extent of entrepreneurship and entrepreneurial forms.

I think that I've come to these views because, over time, looking at different types of entrepreneurs (management buyouts, serial entrepreneurs, returnee entrepreneurs, academic spin-offs, entrepreneurship in family firms) in various contexts, that we have a very fragmented understanding of context and that there has been very little work to join the dots. This is a major challenge as the interplay of different dimensions of context and different types of entrepreneurs is complex but unless we start to address this challenge our insights will remain limited and policy prescriptions may be faulty. Erkko Autio is doing work that tries to address configurations of context but I'm not sure that this fully addresses all dimensions or the variety of entrepreneurial types.

\section{Contexts matter: why all of a sudden and which ones?}

For some time, entrepreneurship scholars have indicated that context matters (Davidsson 2003; Ucbasaran, Westhead and Wright 2001) - picking up a theme which gained importance in general management research at the turn of the century (Bamberger 2008; Johns 2001) and which, to some extent, can be traced back to the German historical school as represented by Gustav Schmoller in the nineteenth century (Schmude, Welter and Heumann 2008) and to German historical sociologists such as Max Weber (Jones and Wadhwani 2006). Already in 2006, Geoffrey G. Jones and Daniel Wadhwani argued that 'historical research may help management researchers to understand how entrepreneurship needs to be understood within the context of time and place'. Since our 2011 context papers (Welter 2011; Zahra and Wright 2011) this theme has been taken up by several entrepreneurship scholars. For example, van Gelderen and Masurel (2012) edited a book on entrepreneurship and context which drew attention to the various meanings and roles, as well as the importance of context in entrepreneurship studies' (p. 1). Spedale and Watson (2013) show how we can move beyond the artificial separation of 'context' and 'individual' and instead arrive at a more realistic picture of entrepreneurial actions. De Bruin and Lewis (2015) and Shaw and de Bruin (2013) suggest that consideration of context can advance research on social entrepreneurship. Chalmers and Shaw (2015) elaborate on methodological challenges in contextualizing. Su, Zhai and Landström (2015) illustrate how context (in this case the Chinese context) is reflected in some of the themes Chinese entrepreneurship researchers study. McKeever, Jack and Anderson (2015) highlight the complex and recursive interrelationship between contexts and entrepreneurs, drawing our attention to the dynamics of a context-perspective on entrepreneurship, whilst Korsgaard, Ferguson and Gaddefors (2015) emphasize the links between contexts and opportunity creation of rural entrepreneurs.

Friederike: Why is it that context has (re-)emerged in entrepreneurship research as one of the hot topics? I am still puzzled as to why all of a sudden there's this huge 
interest in all things context. And don't we risk a superficial and diluted discussion around this? One where context becomes just another of these 'must tick-this-off when submitting to a journal' box?

Bill: Well, one just needs to look at who is writing about context. These authors are non-US authors, for the most part. It is mostly a European discussion. I have a USA background, but, now, I'm at Copenhagen Business School (CBS), in a European context, where, the discussion of context is part of a normal discussion of what entrepreneurship is. So, I think that one of the reasons that context matters, now, more, is that the discussion is occurring because of individuals who are outside of the North American 'taken-for-granted' assumptions about what kinds of contexts matter. I'm going to address this more, later, in a different way.

Mike: I'm not sure why the sudden surge in interest in context. To some extent I feel we've been like Moliere's Bourgeois Gentilhomme: 'il y a plus de quarante ans que je dis de la prose sans que j'en susse rien' - we've been researching context without realizing or acknowledging it for years. Perhaps we, at last, have recognized that evidence and theories based in the US are not necessarily applicable elsewhere - or maybe I should say, US reviewers and journals have come to accept that this is not the case. From that beginning, I think it has opened up a search for dimensions of that context. I guess also that authors have begun to theorize the different relationships between different context and entrepreneurial activities, rather than just applying hypotheses developed in the US into other contexts.

Friederike: Anyway, there seems to be general agreement now in the field that context is important. But, do we agree on which context/s to take into account? Re-reading our context writings (Welter 2011; Welter, Brush and de Bruin 2014; Welter and Xheneti 2013; Zahra and Wright 2011; Zahra, Wright and Abdelgawad 2014), my feeling is 'No, we don't agree'. To me it looks a bit like you, Mike and I have different understanding of what context is/should be in entrepreneurship research. Mine seems to be broader and encompassing more than the institutional, business, industry and organizational contexts - probably more 'weird' contexts for an entrepreneurship researcher as they are 'outside' the business world. Or do I misinterpret? Is our understanding more similar than I envisage? Complementing each other? I stand to be corrected . . .

Mike: The recent paper I did with other colleagues in Research Policy extends some of the contextual aspects (Autio et al. 2014). My 2013 Journal of Management Studies paper with Hoskisson et al. also deepens the variety of context in emerging economies (Hoskisson et al. 2013). I'm quite open to a range of different approaches to context beyond the ones I've looked at so far ... and I'm also open to a broad definition of what entrepreneurial activity means beyond start-ups.

Friederike: Isn't it interesting that most of our context thinking stems from research in 'other' contexts, such as emerging market economies? For me proof that we need to leave our comfort zones in order to recognize what fits and what not. 
Bill: One of the ideas that I want to have pondered is this: the generalizability of difference. We don't really have much thought about differences and how we make sense of differences in our findings. We are always looking for commonalities and generalizable insights. I think we have some difficulty presenting the generalizability of difference. We are somewhere in the discussion between 'all contexts are unique' and 'all contexts are similar'. Hmmm. I'm thinking, now, about what the 'context of contexts' would be about. We are contextualizing context, and, I think, that inherently orients one more towards 'contexts are unique'. Anyway, I'm going to play more, later, with this idea about difference, and, what it means to talk about variation in the nature of entrepreneurship, as a phenomenon.

\section{How to contextualize theories}

[T] here is a need to theorize context rather than leave it as some kind of kitchen sink dumping ground standing behind all our foreground theories and explanations. (Pollitt 2013b, p. 95)

Mike: For me, an issue with context heterogeneity is that we haven't particularly done a great deal to examine the interactions between different types of context, which may highlight conflicts and complementarities. So, how do the different dimensions of context interact with each other? Further, what are the most common and effective configurations? How do contextual dimensions interact with other levels of analysis, notably, firm, team and individuals?

Friederike: The configuration idea definitely needs to be discussed further. When I read your suggestion to discuss 'configurations of contexts', my first reaction was this won't work. Can we really elaborate configurations of context(s)? Isn't that contradicting the dynamics of contexts and temporal aspects? I am more comfortable with seeing contexts as something which is fluid and changeable - although there may be elements that are more stable than others. Difficult to disentangle; and I believe also a challenge to research empirically.

When it comes to interactions, we need to pay much more attention to the multiplicity of contexts. An individual works in particular contexts (a firm, an industry, a culture, a region, a community), she is influenced by each of these contexts, interprets and make sense out of her contexts and simultaneously provides the contexts for others (as boss, as colleague, as entrepreneur, as family member and so on). I really like what Clarke (2013, p. 22) suggests, namely 'thinking contextually', which to him 'certainly demands more than a conventional approach to naming or even describing contexts before the real business of analysis takes place'. He points out that by thinking contextually we will refute 'mono-causal and linear accounts of agency and action' (Clarke 2013, p. 31). For me, his ideas highlight a fundamental issue in regards to the interactions between contexts: those can be all sorts of things - contexts can supplement or complement, but also contradict or antagonize each other. And that at different levels! And of course, we shouldn't forget the 
agency of entrepreneurs - they can change and influence contexts, especially so, if we accept contexts as something which is also interpretative and constructed.

Bill: So, can we say that discussions of context sensitize one to looking for differences in the phenomenon? What is particular to this situation and how is it similar or not to other situations? We so yearn for generalizability. Yes? That what I find in my data might have some relevance to other situations? That I can offer some insights that others might find useful? Maybe 'generalizability', now, needs to be 'contextualized' to a great degree. Maybe we need to offer more specific descriptions of what the situations, are, that we find our results applicable to. There is a sense, then, of humility in our findings. For example, contextualizing our findings, then, means that, in an obvious example, insights from Silicon Valley may not transfer to any other part of the world. Lessons from Silicon Valley may be lessons useful to no one else outside of that location. When we contextualize 'high growth firms', then, those firms might be very, very different depending on where they are located, when they were started (so, time and history are critical as aspects of context), and, who-why-when-what-how become important variables in the discussion. And, the idea of 'high growth firms' is itself, an idea that comes out of a particular context and value system where 'high growth firms' may be given more prominence than other kinds of firms.

Friederike: I couldn't agree more! This is always an issue when governments want good practice examples of what works elsewhere in fostering small firms and entrepreneurship ... I always tell them that they cannot transfer policies, but may have a close look at the constitutive elements of such policies. A particular good example is the very successful German Mittelstand - over the past years, we have had several delegations from around the world, visiting our institute and each of them asking for the recipe of fostering a vibrant Mittelstand in their own countries ... contexts! You can't take the German small business sector outside its context and you can't understand it without looking at the social, historical, temporal, institutional and organizational contexts.

Bill: So, to contextualize is also to consider what we value and find important to focus on. I think that when we introduce, for example, studies of firms in Africa, then, we have to celebrate the differences in cultural, political, regulatory, competitive and so on, ways that entrepreneurship occurs. What relevance does the Silicon Valley model have for anyone else? It is unique to that location. What is generalizable about that context? And, then, what is generalizable about contexts in Eastern Europe, or the Middle East, or South Asia?

For me, this gets back to 'critical mess' arguments I have made - that our field just needs more evidence, more data, about various entrepreneurships that exist (Gartner 2006). We simply do not know enough about the variation in entrepreneurial phenomena that exist in this world. I will offer this straw dog that: we simply generalize our own particular situation as similar to other contexts - and they are not the same. Difference matters. And, we may just need to spend more 
time publishing articles where these differences (no matter how small or trivial we might, at this point, perceive them to be) are described and presented. Hmmm. I could poke a little at the problem of requiring most articles to have some theoretical underpinnings as diminishing chances for publishing articles where the insights are about uniqueness and difference. Aren't theories about generalizability? If $\mathrm{X}$ happens, then, we will see Y? And, aren't we, then, looking always for more X's in this world? But, what if there is only one $\mathrm{X}$ to $\mathrm{Y}$ ? What if there are different situations and relationships that are truly unique? What can we learn from that?

So, this comes down to my hope for theories of difference. I assume, on some level, that entrepreneurial situations have, in some facet of themselves, difference (be it in time, location, motivation, strategy, resources and so on) that makes each situation, unique. How do we pay attention to that? And, then, how do we celebrate those differences and talk about them in a way that could actually be generalizable?

Friederike: Maybe a first step towards theories of difference is acknowledging that contexts are something which is not simply 'out there', but which is also created by us. Remember, Bill, that in our recent workshop on the future of entrepreneurship research at the University of Siegen, we discussed that context is also something which is 'inside' a person or stems from the person's understanding of context (which contexts matter, for example, for an entrepreneur, which ones are considered important by an entrepreneurship scholar? Is there a fit or a misfit between both groups?). That means language and interpretations of context matter interestingly something which is taken up in commonplace definitions of context. ${ }^{1}$ We touched upon contexts and identity building and the construction of contexts by individuals and so on. I believe these issues are under-researched at the moment when it comes to entrepreneurship research, although this is important because it also influences how we theorize and empirically research contexts.

Interestingly, the social construction of context has been widely discussed in other disciplines, notably so in informatics - I only came across these articles by chance, through a very general literature search on 'context' (isn't it telling also: we don't talk to each other across disciplinary boundaries?). Much of what has been written there resonates with my understanding of the 'subjectivity' of context. Akman (2000) has published a really interesting review, highlighting how our understanding and interpretation of words, sentences and situations are not only influenced by the respective contexts, but also create these contexts. So, no two contexts are alike as we individually reinterpret and make sense of them.

Another issue is whether we can stretch existing theories to incorporate context specificities - for me, this also is a step towards Bill's idea to develop theories of differences. I certainly think we can use and stretch existing theories to incorporate differences - we just need to be willing! Most of our theories stem from Western contexts, maybe even from the US context. So, they give us a very narrow picture of how entrepreneurs behave, what they do, how they use resources and which resources they draw on, how they grow their businesses and so on. I see two ways 
forward: One is to take back to mainstream entrepreneurship what research on different contexts brings to the table. The research on women's entrepreneurship is, for me, an excellent example of this: In that field, we have suggested a framework which allows us to theoretically grasp the multiplicity of contexts and their interactions (Brush, de Bruin and Welter 2009) - why not use those frameworks for all of entrepreneurship? The same holds true for research on ethnic/minority entrepreneurship, where Kloosterman and colleagues have developed the framework of mixed embeddedness arguing for a close look at the interactions of migrants within their economic, social and institutional contexts (Kloosterman, Van der Leun and Rath 1999). And, secondly, there are several theories by now, that already contextualize or would allow for contextualizing. For example, concepts like bricolage (Baker and Nelson 2005), entrepreneurial resilience and resourcefulness (Corbett and Katz 2013; Misra and Kumar 2000; Powell 2011) have a lot to say about (successful) resource acquisition in different social, spatial and institutional contexts - but there may be a tendency to see those approaches as too narrow and restricted to a specific target group (those in need - those who can't do resource acquisition properly. . .).

Mike: These latter theories also give rise to research agendas on the limitations of the context they explore. For example, for me bricolage doesn't have much to say about scaling up challenges relating to entrepreneurship.

Friederike: But by now bricolage has been explored in many different contexts. Anyway, besides working on theories of difference, I think we also need to show that, and how, contextualizing is not the 'enemy of big generalizations' (Pierre 2013). Somehow, these two issues go hand in hand for me. So, we need to discuss what does generalization mean once we contextualize? Pollitt (2013c) talks about scale/levels on which contextual factors operate. Public policy research uses micro, meso, macro frameworks to disentangle context factors, focusing mainly on meso research as a level where 'a considerable degree of generalizing can be achieved and yet contextual peculiarities can still be given a place. Middle-level generalizations, it is claimed, can be transferred (cautiously) between similar contexts, once those contexts are defined and integrated into the relevant explanatory theory' (Pollitt 2013a, p. 416). Can we transfer this to entrepreneurship research? That seems to be difficult because entrepreneurship is something which depends on both persons, that is, the micro level, and their wider contexts at meso and macro level. Maybe one idea would be to identify contexts that are more or less there 'forever' - and others that are more short-lived. In a way, this is also something that goes in the direction of configurations of contexts? Not sure yet . . . but Pollitt (2013b, p. 94) also suggests that we can do something he labels 'contextualized generalizations'. And I think this is exactly what Mike is asking us to discuss now.

Mike: Maybe we need to think in terms of the interaction of exogenous and endogenous dimensions of context then? I think that the individual dimension of context is not just about the way they perceive context but also has something to do with the variety of individual entrepreneurial goals. Entrepreneurs do not all 
have the same goals and their different goals provide different contexts for their entrepreneurial behaviour.

Can we tease out what aspects of entrepreneurship transcend context and which aspects are context-dependent? I think we should also explore not just whether theories and evidence from one context translate to another context, and which context, but also the dark side. That is, is transferring inappropriate theories and evidence 'neutral' or does it have negative consequences?

Friederike: Big questions! Again, for me this has a lot to do with generalizability. Maybe looking at each of the contexts in turn will help: When we look at individual behaviour, is there something universal across cultures and countries? Difficult to say, because we also know that, for example, what we would consider illegal entrepreneurship may be considered legal or tolerated elsewhere. But the fundamentals of how individuals think and behave are similar, or? Cognitions may differ because meanings and interpretations matter; they in turn are context-dependent and they also change over time. Ok, I admit this is not yet really helpful in answering your questions - but then, your questions set out some of the challenges researchers will have to tackle when developing context theories.

Mike: Perhaps betraying my training as an economist, I also think we need to consider the 'so what?' question. In other words, does analysis of different dimensions of context matter for understanding the performance outcome of entrepreneurial ventures rather than just their creation? This is reminiscent to me of all the work on the contingency theory of organizations in the 1970 s and 1980 os - lots of work on the contingent (that is, contextual) effect on the structure of organizations but very little on performance effects. Interestingly, this work did start out by looking at structural (exogenous) factors but subsequently looked at endogenous issues like internal culture of organizations.

\section{How to contextualize in practice}

Mike: How does one research these interdependencies of context and these different levels? What are the roles of qualitative and quantitative work (and which sorts)? What are the challenges and how can they be overcome?

Friederike: Multi-level modelling? I am not an expert on that, but have listened to and reviewed several papers over the past years, which set out multi-level models as one way to deal with the interdependencies of contexts and its manifold, cross-level nature. I'd personally go for in-depth work at different levels and with different methods, for example, participant observations, interviews or focus groups and many more. We may actually learn a lot here from anthropology. And, I see a great opportunity for contextual research because we need both more 'quantitative' and 'qualitative' work - we finally can start reconciling both research approaches and look for their contributions in their own rights. 
One of the challenges - or advantage? - for our empirical research is that we can't decontextualize ourselves. We are shaped by our contexts (also see Zahra 2007), and we often don't see this. How to tackle this? What does it mean for our research? Hjorth, Jones and Gartner (2008, p. 82) talk about contextualized research as research that is grounded deeply in the context of disciplines, drawing on and simultaneously contributing to social and human sciences. So, can we suggest that contextualized research is one which per nature (definition) is interdisciplinary/multidisciplinary? Together with the multi-level approaches, this would have implications for empirical research - make it more complicated and complex and at the same time fascinating. I do think the entrepreneurship field is ideally suited for contextualized (interdisciplinary) research because we ourselves stem from so many different disciplines. And we could become so much more relevant (again) (Baker and Welter 2015) ...

Another question I recently have been asked is 'How do you develop contextualized hypotheses?' A tricky issue, same can be said for the issue of 'theorizing context'. In my eyes, many of us seem to misunderstand what 'theorizing context' means in practice. In papers submitted to ET\&P or elsewhere, I too often see a section on 'the research context' or 'the context in'. When it comes to hypotheses development, researchers often tag 'in China', 'in Germany', 'in the tech industry' and similar onto hypotheses. This is not contextualizing - we definitely need to push this further. Context research from other disciplines argues for 'greater precision' in identifying contexts and operationalizing it, because without 'some precision it is hard for contexts to enter into theories. They tend to remain a passive "background"' (Pollitt 2013a, p.416). How can we achieve similar precision for entrepreneurship research? I think through deep engagement with contexts and then integration into our research as a lens, not as a simple variable. For hypotheses development, this would mean engaging with the relevant contexts and trying to tease out why one may expect different results because of these contexts.

Something else arises as a challenge from that - variables/measurements of contexts: If we accept that contexts are also constructed, this asks for contextualized variables (measurements), contradicting research which normally would assume that variables are the 'same kind of "thing" across a wide range of contexts, and to vary in value (quantity) but not in essence' (Pollitt 2013a, p.418). We have grappled with this in a project studying trust in different cultures: does a Russian entrepreneur talk about the same thing compared to a German entrepreneur? How can we solve this? Pollitt (2013a, p. 419) suggests a more 'nuanced and inclusive approach', trying to reconcile the usual approach where we apply the same measures/variables across all contexts with what he labels 'radical contextualism', reflecting a qualitative and interpretative narrative.

Bill: Well, I will continue to beat the drum on this: If differences matter, then, the goal becomes discerning what the differences actually are, and, why these differences would matter. As Mike suggests, we have to ask 'So what?' Indicating that, 
'everything is unique', does not provide much insight into suggestions for practice. I assume that we believe that one of the values of gaining knowledge and insight through research is to inform others about more viable or plausible ways of acting in this world. So, then, the challenge is not in assuming that all contexts are inherently different (due to time, place, culture, and so on) but, that, one might find that some characteristics of the context can also be comparatively understood. I think this can be a bit tricky to facilitate. For example are we aiming for comparative efforts in a similar vein as Hofstede's (1984) dimensions for comparing cultures? Does his work contextualize or decontextualize the ability to generate insights? So, while Hofstede's dimensions of culture might be characteristics that we would want to comparatively contextualize, our ability to understand it comparatively, outside of the specific contexts of what culture actually is, in the context of a specific culture, can be problematic. And, yet, we must try.

\section{Moving forward}

Stop. For a moment:

Look. Listen. Pay attention.

What did you find here?

NOTE

1 Merriam-Webster defines context as ' 1 : the parts of a discourse that surround a word or passage and can throw light on its meaning; 2: the interrelated conditions in which something exists or occurs: environment, setting'. See: www. merriam-webster.com/dictionary/context (accessed 26 November 2015).

\section{References}

Akman, Varol (200o), 'Rethinking context as a social construct', Journal of Pragmatics, 32 (6), 743-759. Autio, Erkko, Martin Kenney, Philippe Mustar, Don Siegel and Mike Wright (2014), 'Entrepreneurial innovation: The importance of context', Research Policy, 43 (7), 1097-1108.

Baker, Ted and Reed E. Nelson (2005), 'Creating something from nothing: Resource construction through entrepreneurial bricolage', Administrative Science Quarterly, 50 (3), 329-366.

Baker, Ted and Friederike Welter (2015), 'Bridges to the future', in Ted Baker and Friederike Welter (eds), The Routledge Companion to Entrepreneurship, London: Routledge, pp.3-17.

Bamberger, Peter (2008), 'From the editors: Beyond contextualization: Using context theories to narrow the micro-macro gap in management research', Academy of Management Journal, 51 (5), 839-846.

Brush, Candida G., Anne de Bruin and Friederike Welter (2009), 'A gender-aware framework for women's entrepreneurship', International Journal of Gender and Entrepreneurship, 1 (1), 8-24.

Carter, Nancy M., William B. Gartner and Paul D. Reynolds (1996), 'Exploring start-up event sequences', Journal of Business Venturing, 11 (3), 151-166.

Chalmers, Dominic M. and Eleanor Shaw (2015), 'The endogenous construction of entrepreneurial contexts: A practice-based perspective', International Small Business Journal, published online before print 21 September 2015, doi: 10.1177/0266242615589768.

Clarke, John (2013), 'Contexts: Forms of agency and action', in Christopher Pollitt (ed.), Context in Public Policy and Management: The Missing Link?, Cheltenham, UK and Northampton, MA, USA: Edward Elgar Publishing, pp. 22-34. 
Corbett, Andrew C. and Jerome A. Katz (eds), (2013), Entrepreneurial Resourcefulness: Competing With Constraints, Bingley: Emerald.

Davidsson, Per (2003), 'The domain of entrepreneurship research: Some suggestions', in J.A. Katz and D.A. Shepherd (eds), Cognitive Approaches to Entrepreneurship Research, Amsterdam: JAI, pp. 265-314.

De Bruin, Anne and Kate V. Lewis (2015), 'Traversing the terrain of context in social entrepreneurship', Journal of Social Entrepreneurship, 6 (2), 127-136.

Gartner, William B. (1982), An empirical model of the business startup, and eight entrepreneurial archetypes. Unpublished Dissertation, Seattle, WA: University of Washington.

Gartner, William B. (1985), 'A conceptual framework for describing the phenomenon of new venture creation', Academy of Management Review, 10 (4), 696-706.

Gartner, William B. (1988), “Who is an entrepreneur?" is the wrong question', American Journal of Small Businesses, 12 (4), 11-32.

Gartner, William B. (2006), 'A “critical mess” approach to entrepreneurship scholarship', in Anders Lundström and Sune Halvarsson (eds), Entrepreneurship Research: Past Perspectives and Future Prospects (Vol. 2), Hanover, MA: NOW, pp. 73-82.

Gartner, William B. (2008), 'Variations in entrepreneurship', Small Business Economics, 31 (4), 351-361.

Gartner, William B. and Sue Birley (2002), 'Introduction to the special issue on qualitative methods in entrepreneurship research', Journal of Business Venturing, 17 (5), 387-395.

Gartner, William B., Nancy M. Carter and Paul D. Reynolds (2004), 'Business startup activities', in William B. Gartner, Kelly G. Shaver, Nancy M. Carter and Paul D. Reynolds (eds), Handbook of Entrepreneurial Dynamics: The Process of Business Creation, Thousand Oaks, CA: Sage pp. 285-298.

Gartner, William B., T.R. Mitchell and K.H. Vesper (1989), 'A taxonomy of new business ventures', Journal of Business Venturing, 4 (3), 169-186.

Hjorth, D., C. Jones and W.B. Gartner (2008), 'Introduction for "recreating/recontextualising entrepreneurship"', Scandinavian Journal of Management, 24 (2), 81-84.

Hofstede, Geert (1984), Culture's Consequences: International Differences in Work-Related Values, Newbury Park: Sage.

Hoskisson, Robert E., Mike Wright, Igor Filatotchev and Mike W. Peng (2013), 'Emerging multinationals from mid-range economies: The influence of institutions and factor markets', Journal of Management Studies, 50 (7), 1295-1321.

Johns, Gary (2001), 'In praise of context', Journal of Organizational Behavior, 22 (1), 31-42.

Jones, Geoffrey and R. Daniel Wadhwani (2006), Entrepreneurship and Business History: Renewing the Research Agenda, Harvard: Division of Research, Harvard Business School. Available at: http:// hbswk.hbs.edu/item/entrepreneurship-and-business-history-renewing-the-research-agenda (accessed 15 June 2016).

Kloosterman, R., J. Van der Leun and J. Rath (1999), 'Mixed embeddedness: (In)formal economic activities and immigrant businesses in the Netherlands', International Journal of Urban and Regional Research, 23 (2), 252-277.

Korsgaard, Steffen, Richard Ferguson and Johan Gaddefors (2015), 'The best of both worlds: How rural entrepreneurs use placial embeddedness and strategic networks to create opportunities', Entrepreneurship \& Regional Development, 27 (9-10), 1-25.

McKeever, Edward, Sarah Jack and Alistair Anderson (2015), 'Embedded entrepreneurship in the creative re-construction of place', Journal of Business Venturing, 30 (1), 50-65.

Misra, Sasi and E. Sendil Kumar (200o), 'Resourcefulness: A proximal conceptualisation of entrepreneurial behaviour', Journal of Entrepreneurship, 9, 135-154.

Pierre, Jon (2013), 'Context, theory and rationality: An uneasy relationship?', in Christopher Pollitt (ed.), Context in Public Policy and Management: The Missing Link?, Cheltenham, UK and Northampton, MA, USA: Edward Elgar Publishing, pp. 124-130. 
Pollitt, Christopher (2013a), 'Context: What kind of missing link?', in Christopher Pollitt (ed.), Context in Public Policy and Management: The Missing Link?, Cheltenham, UK and Northampton, MA, USA: Edward Elgar Publishing, pp. 415-422.

Pollitt, Christopher (2013b), 'First link', in Christopher Pollitt (ed.), Context in Public Policy and Management: The Missing Link?, Cheltenham, UK and Northampton, MA, USA: Edward Elgar Publishing, pp. 88-97.

Pollitt, Christopher (2013c), 'Preface: Context - A missing link?', in Christopher Pollitt (ed.), Context in Public Policy and Management: The Missing Link?, Cheltenham, UK and Northampton, MA, USA: Edward Elgar Publishing, pp. xv-xx.

Powell, Erin E. (2011), Weathering the gale: Toward a theory of entrepreneurial resourcefulness and resilience. Dissertation, North Carolina State University. From: http://proquest.umi.com/pqdl $n k$ ?did $=2485153441 \& F m t=2 \&$ clientI $d=79356 \& R Q T=309 \& V N a m e=P Q D($ accessed 25 April 2016).

Schmude, Jürgen, Friederike Welter and Stefan Heumann (2008), 'Entrepreneurship research in Germany', Entrepreneurship Theory and Practice, 32 (2), 289-311.

Shaver, Kelly G. and Linda R. Scott (1991), 'Person, process, choice: The psychology of new venture creation', Entrepreneurship Theory and Practice, 16 (2), 23-43.

Shaw, Eleanor and Anne de Bruin (2013), 'Reconsidering capitalism: The promise of social innovation and social entrepreneurship?', International Small Business Journal, 31 (7), 737-746.

Spedale, Simona and Tony J. Watson (2013), 'The emergence of entrepreneurial action: At the crossroads between institutional logics and individual life-orientation', International Small Business Journal, 32 (7), 759-776.

$\mathrm{Su}$, Jing, Qinghua Zhai and Hans Landström (2015), 'Entrepreneurship research in China: Internationalization or contextualization?', Entrepreneurship \& Regional Development, 27 (1-2), $50-79$.

Ucbasaran, Deniz, Paul Westhead and Mike Wright (2001), 'The focus of entrepreneurial research: contextual and process issues', Entrepreneurship: Theory and Practice, 25 (4), 57-78.

van Gelderen, Marco and Enno Masurel (eds), (2012), Entrepreneurship in Context, Abingdon: Routledge.

Welter, Friederike (2008), 'Entrepreneurship in its context(s): a review'. Paper presented at the NSF-DFG Conference 'Contextualizing Economic Behaviour', New York, NY.

Welter, Friederike (2011), 'Contextualizing entrepreneurship - conceptual challenges and ways forward', Entrepreneurship Theory and Practice, 35 (1), 165-184.

Welter, Friederike (2016), 'Wandering between contexts', in David Audretsch and Erik Lehmann (eds), The Routledge Companion to Makers of Modern Entrepreneurship, London: Routledge, forthcoming.

Welter, Friederike and David Smallbone (2011a), 'Institutional perspectives on entrepreneurial behavior in challenging environments', Journal of Small Business Management, 49 (1), 107-125.

Welter, Friederike and David Smallbone (eds), (2011b), Handbook of Research on Entrepreneurship Policies in Central and Eastern Europe, Cheltenham, UK and Northampton, MA, USA: Edward Elgar Publishing.

Welter, Friederike and Mirela Xheneti (2013), 'Reenacting contextual boundaries - Entrepreneurial resourcefulness in challenging environments', in Andrew C. Corbett and Jerome Katz (eds), Entrepreneurial Resourcefulness: Competing with Constraints (Vol. 15), Bingley: Emerald, pp. 149-183.

Welter, Friederike, Candida G. Brush and Anne de Bruin (2014), 'The gendering of entrepreneurship context', Working Paper, 1/2014, Bonn: IfM Bonn.

Wright, Mike, James J. Chrisman, Jess H. Chua and Lloyd P. Steier (2014), 'Family enterprise and context', Entrepreneurship Theory and Practice, 38 (6), 1247-1260.

Zahra, Shaker A. (2007), 'Contextualizing theory building in entrepreneurship research', Journal of Business Venturing, 22 (3), 443-453. 
Zahra, Shaker A. and Mike Wright (2011), 'Entrepreneurship's next act', Academy of Management Perspectives, 25 (4), 67-83.

Zahra, Shaker A., Mike Wright and Sondos G. Abdelgawad (2014), 'Contextualization and the advancement of entrepreneurship research', International Small Business Journal, 32 (5), 479-5oo. 